This work is licensed under a Creative Commons Attribution 4.0 International License https://creativecommons.org/licenses/by/4.0/

\title{
MOOC-LECTURE IN DIGITAL ACADEMIC DISCOURSE: KEY FEATURES
}

\author{
N.V. Panich \\ Moscow State Institute of International Relations (University), \\ 76 Prospect Vernadskogo, Moscow, 119454 Russia
}

\begin{abstract}
The article considers the traits of digital academic discourse and the discursive features of MOOC lectures, i.e. video lectures from massive open online courses (MOOCs), which are described as a subgenre of distance lectures. The research bears considerable relevance given the need for the analysis of transformation processes in academic discourse amid the widespread use of information and communication technologies in the higher education system and the advance of online learning. The article describes the evolution of lectures from classroom (analogue) to digital ones, with the latter defined as a genre of academic discourse. The research studies video lectures presented by major British and American universities on the Coursera and EdX websites. It presents some distinguishing characteristics of a MOOC-lecture, specifying, among others, its extralinguistic traits which impact on its linguistic features, particularly the addressee factor. The theoretical perspective on the matter can be applied in linguistic disciplines, which aim at undergraduate and postgraduate students opting for the scientific path in the international context.
\end{abstract}

Key Words: digital academic discourse, computer-mediated academic communication, digital lecture, MOOC-lecture, Massive Open Online Courses

\section{ДИСКУРСИВНЫЕ ХАРАКТЕРИСТИКИ МООК-ЛЕКЦИИ КАК РАЗНОВИДНОСТИ ДИСТАНТНОЙ ЛЕКЦИИ В АКАДЕМИЧЕСКОМ ИНТЕРНЕТ-ДИСКУРСЕ}

\author{
Н.В. Панич
}

Московский государственный институт международных отношений (университет) МИД России, Москва, 119454, пр. Вернадского 76

Аннотация. Настоящая статья посвящена рассмотрению дискурсивных характеристик академического интернет-дискурса (АИД) и его субжанра - интернет-лекиий, размещённых на сайтах массовых открытых онлайн-курсов (МООК-лекиий), которые представлены как разновидность дистаниионных академических текиий. Актуальность исследования определяется не- 
обходимостью сбормировать представление о трансформационных проиессах в академическом дискурсе в связи с масштабным внедрением информационно-коммуникаиионных технологий в систему высшего образования и последующим развитием онлайн-обучения. В качестве материала исследования использованы Coursera- и Edx-курсы англоязычных лекторов из крупных университетов Великобритании и США. Рассматривается становление дистаниионной (виртуальной) лекиии как жанровой разновидности академического дискурса; МООК-лекиия обособляется от других видов лекиий, выделяется ряд характеристик, которые оказывают воздействие на её языковые параметры, в том числе обосновывается значимость изменений в образе получателя информации. Рассмотрение проблематики с теоретических позиций может иметь прикладное значение для лингвистических дисииплин, в задачи которых входит подготовка научных кадров кработе в международном контексте.

Ключевые слова: дистаницинный академический дискурс, академический интернет-дискурс, МООК-лекция, виртуальная академическая коммуникаиия, эволюиия академического дискурса

\section{Введение}

$\mathrm{B}$ о время пандемии 2020 года академическая среда испытала на себе воздействие вынужденного массового перехода на дистанционный формат образования, который, помимо прочего, предполагал включение в учебный процесс цифрового образовательного контента, который уже был подготовлен и размещён в Интернете. Это вызвало к жизни потребность в осмыслении изменений, которые затрагивают академический дискурс в связи с активным внедрением информационно-коммуникационных технологий в процесс реализации образовательных задач и развитием дистанционного образования, в том числе и на уровне высшей школы. В связи с интеграцией российской образовательной системы в глобальный контекст, где основным языком профессионального общения является английский, интерес представляет в первую очередь реакция англоязычной академической коммуникации на новые обстоятельства развёртывания дискурса.

Целью работы является краткое обобщение теоретических основ изучения академического интернет-дискурса (АИД) и его конститутивных признаков, а также рассмотрение становления его субжанровой разновидности - МООК-лекции, то есть виртуальной лекции, размещённой на сайте массовых открытых онлайн-курсов, и её особенностей. В качестве материала исследования использованы лекции англоязычных преподавателей крупных университетов Великобритании и США с сайтов Coursera и Edx.

В связи с отсутствием единой позиции среди учёных в отношении содержания понятия «академический дискурс», необходимо уточнить, что в данной работе мы разводим понятия «научный» и «академический дискурс», рассматривая их как смежные, характеризующиеся совпадением ряда функций, но предполагающие комплементарные отношения между коммуникантами. Двигаясь в русле представлений Я.В. Зубковой [3] и отталкиваясь от истоков значения слова «академический» (в Оксфордском словаре английского языка его синонимами являются слова «образовательный» («educational»), «учебный» («instructional») и «педагогический» («pedagogical»)), мы устанавливаем отношения тождества между академическим дискурсом и учебно-педагогическим и считаем, что первый представляет собой социально обусловленную систему организации профессионально-педагогического коммуникативного взаимодействия, протекающего в высшем учебном заведении между преподавателями (адресантами) и студентами (реципиентами) с целью подготовить специалистов высшего уровня квалификации и заложить у реципиента «систему профессиональных знаний и профессионального мышления» [12]. В связи с этим, полностью за рамками рассмотрения остаётся профессиональное устное и письменное общение между исследователями (конференции, доклады, защиты кандидатских и докторских диссертаций, публикации статей, монографии). 
Особенность дистанционной учебно-педагогической коммуникации заключается в том, что формирование академической среды с помощью электронного модуса происходит на стыке виртуального и педагогического, что неизбежно отличает его от традиционного академического дискурса, протекающего непосредственно в здании высшего учебного заведения. Так, с компьютерным АИД сближает 1) дистантный характер взаимодействия участников коммуникации (по времени и/или в пространстве); 2) опосредованность общения аналоговыми и цифровыми средствами коммуникации [7]; 3) значительная степень проницаемости, которую Е.Н. Галичкина определила как принципиальную возможность включения в процесс коммуникации любого человека [2]; 4) «диалектическое единство устной и письменной коммуникации» [4]; 5) потенциальная мультимедийность; 6) иллокутивность, предполагающая диалогичность взаимодействия, то есть личное участие (социально-ролевое или предметное) коммуникантов, наличие ответного действия; 7) глобальность, отсутствие границ, позволяющее осуществлять взаимодействие за пределами своей культуры, и 8) «особая конвенциональность и наличие фиксированных правил общения», нетикет [8]. Несмотря на присутствие схожего признака (кодифицированность речевого взаимодействия), языковые нормы, регулирующие речевую деятельность в рамках двух дискурсов, разнятся и требуют отдельного исследования на эмпирическом материале для определения лингвистического тяготения гибридного дискурса к одному из его составляющих.

Общей для интернет-дискурса и академического дискурса будет интерактивная составляющая, стремление к диалогизации общения как основы взаимодействия и организации отношений участников коммуникации, даже в отсутствие непосредственного контакта между ними.

В то же время некоторые характеристики интернет-дискурса и академического дискурса вступают в определённое противоречие, как, например, симметричность общения. В то время, как Е.Н. Галичкина и Н.А. Лепшеева указывают на присутствие принципиального статусного равноправия у компьютерно-опосредованной коммуникации, в рамках учебно-педагогического дискурса общение участников является ассиметричным и протекает в соответствии с заданными ситуацией ролями, поэтому речь идёт об отсутствии равенства, так как коммуникация фактически представляет собой передачу информации от отправителя (преподавателя) к потребителю (обучающемуся). В этом вопросе нам близко понимание Л.В.Куликовой, которая в своём определении академического дискурса подчёркивала нормативную организацию речевого взаимодействия, «учитывающего статусно-ролевые характеристики основных участников общения [...] в сфере университетского образования) [5, с. 298].

Также, в связи с функционалом, возложенным социумом на систему высшего образования, проблемным, на первый взгляд, представляется однозначное применение к академической среде такого признака интернет-коммуникации, как добровольность контактов [10, с. 24]. Необходимо уточнить, что стоит разграничить образовательный контент, который создаётся изначально под специфику канала передачи информации, и тот, который экстренно переносится в дистанционный формат с применением доступных образовательных технологий и инструментов коммуникации. Мы рассматриваем только электронно-опосредованную академическую коммуникацию, которая изначально предполагала применение информационно-коммуникативных технологий.

Учитывая, что АИД, как было указано выше, принадлежит к институциональным дискурсам, для выделения его типологических характеристик к нему применена схема системообразующих признаков, предложенная В.И.Карасиком в рамках субъектного подхода к дискурсу [6]. Участниками академической коммуникации являются статусно квалифицированные участники: преподаватель-лектор (агент), принадлежащий структурному объединению по специальностям (кафедра) и направлениям (факультет) и обучающийся (клиент), дистантное двунаправленное взаимодействие которых преследует целью содействовать овладению реципиентом профессиональных знаний, умений и навыков, и достичь преемственности и непрерывности передачи знаний [13], причём оба коммуниканта осознают и поддерживают значимость образовательного процесса. С традиционным учебно-педагогическим дискурсом АИД сближают отношения постоянного взаимооценивания агента и клиента, причём с акцентуацией направленности в сторону второго, то есть активность преподавателя в вопросе оценивания будет ситуативно более значима. 
Пространственно-временные рамки носят условный характер, учитывая виртуальность интернет-среды, где разворачивается АИД. Так, А.А. Селютин указывает на «размытость» структуры хронотопа, при этом географическая удалённость коммуникантов не влияет на доступность информации, а представление о времени носит субъективированный характер [9, с. 123].

Своеобразным ответом на использование нового канала для передачи значимой в учебном плане информации стало становление значительного жанрового разнообразия АИД, что призвано отразить многообразие форм институционального взаимодействия в этой среде: онлайн-лекции и вебинары, академические интернет-форумы, онлайн-конференции, академические блоги и т.д. Стоит отметить, что ряд жанров и субжанров представляются аналогичными существующим в оффлайне, но в силу указанных выше параметров, заимствованных АИД из интернет-дискурса, невозможно априори, без сравнения типовых структур (жанровых схем) и устойчивых языковых характеристик, поставить между ними знак равенства.

Кратко остановимся на эволюции академической лекции, которая и привела к возникновению такой её субжанровой разновидности, как МООК-лекция. С момента своего появления в XII веке лекция остаётся неизменной составляющей традиционной академической коммуникации, отличительной чертой которой является двойственность её природы: она занимает промежуточное положение между письменной и устной формой языка. Ей свойственна высокая информационная плотность материала, которая характерна скорее для академической прозы, но при этом преподнесение материала идёт в условно диалогической форме («монолог в диалоге»), так как от неё ожидается «вовлечение слушателей в общение» для эффективной реализации коммуникативных задач. «Объяснение как форма обращения к сознанию слушателя требует очевидного диалога и, соответственно, диалогических языковых моделей, свойственных устной речи» [11]. Сделаем оговорку, что за рамками работы остаются публичные лекции в рамках общественной просветительской деятельности. Хотя они также ставят своей задачей повышение образовательного уровня, но они не преследуют цель на системной основе содействовать достижению, а затем и сертифицировать определённый уровень профессиональной подготовленности специалиста.

С точки зрения своей базовой функции как транслятора знаний лекция трансформировалась незначительно, несмотря на некоторые видоизменения под социальный заказ. К настоящему моменту она перестала рассматриваться как единственный источник получения знаний и более востребованным становится интегрирование диалогической составляющей, что сближает её с семинарскими занятиями (обучающиеся вовлекаются в дискуссию, выполняют задания лектора, могут выступать как со-лекторы). Тем не менее, в условиях интернет-коммуникации из-за возможности асинхронного взаимодействия с широкой аудиторией задействован именно потенциал лекции как средства массового обучения.

Несмотря на необходимость адаптировать лекционный материал в связи с размыванием образа потенциального реципиента информации (она доступна миллионной аудитории по всему миру), лекции на МООК-платформах отчасти сохраняют традиционные структурные и логические особенности: в них присутствуют определённые компоненты (вступительная часть, тематическое освещение различных вопросов, подведение итогов), наличествует преемственность и системность. Типологически преобладают такие традиционные разновидности лекции, как информационная и обзорная, также могут присутствовать вводные лекции, которые призваны сформировать у обучающегося представление о лекторе, структуре курса, значимости учебной дисциплины). Тем не менее, стоит подчеркнуть, что наиболее трудные для восприятия смысловые блоки часто переведены в письменную форму, особенно установочные моменты вступительной лекции, касающиеся задач и структуры курса. В целом можно сказать, что происходит перераспределение информации между устной и письменной формой, что связано с трудностями в поддержании дистантного контакта с условным обучающимся и вызванной этим необходимостью представлять информацию более дробно и достаточно часто обращаться к категории мультимодальности для сохранения доступности и наглядности лекций.

Некоторые виды лекций из типологии Н.В. Бордовской и А.А. Реан [1] - лекция с запланированными ошибками, бинарная лекция (сократическая беседа преподавателей), лекция-конферен- 
ция между обучающимися (включает презентацию докладов и дискуссию) - не представлены в силу специфики организации, требующей поддержания неопосредованного диалога. Можно отметить попытку нескольких лекторов придать лекции проблемный характер и через соответствующий форум подтолкнуть обучающихся к совместному поиску решения. Или на том же форуме организовать подобие консультации и в вопросно-ответной форме дать требуемые пояснения. Но в обоих случаях за попыткой сохранить информационный функционал академического взаимодействия утрачивается собственно формат устной презентации информации.

Поиск оптимальной стратегии для установления и поддержания контакта с трудно дифференцируемым анонимным реципиентом требует от МООК-лектора, с одной стороны, точного соблюдения этикетных норм при максимальном абстрагировании от любой культурной привязки, и привлечение речевых тактик для обеспечения успешности коммуникации.

В связи с этим можно наметить следующие актуальные перспективы изучения МООК-лекций как субжанра дистанционной лекции:

- $\quad$ анализ речевых тактик, нацеленных на установление и поддержание контакта, в том числе с учётом конкретного типа МООК-лекции;

- выработку свода правил сетевого нетикета, регулирующего академическую коммуникацию в рамках МООК-лекции в англоязычном дискурсе.

\section{Заключение}

Обобщая сказанное выше, можно утверждать, что:

1) академический интернет-дискурс сформировался под воздействием мультимедийных технологий как отдельный, гибридный вид дискурса, вобравший в себя целый ряд признаков обоих своих составляющих и характеризующийся значительным жанровым разнообразием;

2) эволюция традиционной лекции под воздействием глобализационных процессов и технологического развития вызвала к жизни становление МООК-лекции как отдельного субжанра дистантной академической лекции, которая сочетает функционал традиционной лекции и масштабность охвата дистантной, что приводит к формированию собственного набора лингвистических средств для усиления интерактивности и реализации коммуникативно-прагматических задач, стоящих перед адресантом.

(C) Панич Н.В., 2021

\section{Список литературы}

1. Бордовская Н. В. Педагогика: Учебное пособие/ Н. В. Бордовская, А. А. Реан. СПб.: Питер, 2008. 304 с.

2. Галичкина Е. Н. Характеристики компьютерного дискурса [Электронный ресурс] / Е. Н. Галичкина // Вестник ОГУ. 2004. №10. -URL: https://cyberleninka.ru/article/n/harakteristiki-kompyuternogo-diskursa (дата обращения: 01.05.2021).

3. Зубкова Л. И. Конститутивные признаки академического дискурса/ Л. И. Зубкова // Известия Волгоградского государственного педагогического университета. 2009. № 5. С. 28-32.

4. Кутузов А. Б. Коммуникативные особенности дискурса компьютерных сетевых форумов [Электронный ресурс] / А. Б. Кутузов // III Лазаревские чтения. Челябинск. 2006. С. 306-311. - URL: https://www.academia.edu/2984908/\%D0\% 9A\%D0\%BE\%D0\%BC\%D0\%BC\%D1\%83\%D0\%BD\%D0\%B8\%D0\%BA\%D0\%B0\%D1\%82\%D0\%B8\%D0\%B2\%D0\%BD\%D1 \%8B\%D0\%B5_\%D0\%BE\%D1\%81\%D0\%BE\%D0\%B1\%D0\%B5\%D0\%BD\%D0\%BD\%D0\%BE\%D1\%81\%D1\%82\%D0\%B8_\% D0\%B4\%D0\%B8\%D1\%81\%D0\%BA\%D1\%83\%D1\%80\%D1\%81\%D0\%B0_\%D0\%BA\%D0\%BE\%D0\%BC\%D0\%BF\%D1\%8C \%D1\%8E\%D1\%82\%D0\%B5\%D1\%80\%D0\%BD\%D1\%8B\%D1\%85_\%D1\%81\%D0\%B5\%D1\%82\%D0\%B5\%D0\%B2\%D1\%8B \%D1\%85_\%D1\%84\%D0\%BE\%D1\%80\%D1\%83\%D0\%BC\%D0\%BE\%D0\%B2 (дата обращения: 03.05.2021).

5. Куликова Л. В. Коммуникативный стиль в межкультурной парадигме / Л. В. Куликова. Красноярск : Краснояр. гос. пед. ун-т им. В.П. Астафьева, 2006. 392 с.

6. Карасик В.И. Интерпретация дискурса: топик, формат, модус [Электронный ресурс] / В. И. Карасик // Известия ВГПУ. 2015. №1 (96). - URL: https://cyberleninka.ru/article/n/interpretatsiya-diskursa-topik-format-modus (дата обращения: 11.05.2021). 
7. Лепшеева Н. А. Жанровые особенности компьютерного дискурса [Электронный ресурс] / Н. А. Лепшеева// Вестник ЧелГУ. 2009. №43. - URL: https://cyberleninka.ru/article/n/zhanrovye-osobennosti-kompyuternogo-diskursa (дата обращения: 15.05.2021).

8. Моргун Н. Л. Научный сетевой дискурс как тип текста : Дис. ... канд. филол. наук: 10.02.01 / Моргун Наталья Леонидовна. Тюмень, 2002. - URL: https://elibrary.com.ua/m/files/get_file/1541.pdf (дата обращения: 10.05.2021).

9. Селютин А. А. Пространство и время в интернет-коммуникации: влияние постмодернизма / А. А. Селютин // Вестник Челябинского гуманитарного университета, 2012. №6 (260). С. 122-124.

10. Смирнов Ф. О. Национально-культурные особенности электронной коммуникации на английском и русском языке : дис. . канд. филол. наук. / Смирнов Федор Олегович. Ярославль, 2004. 224 с.

11. Таланина А. А. Онлайн-лекция как жанр интернет-дискурса [Электронный ресурс] / А. А. Таланина // МИРС. 2018. №2. - URL: https://cyberleninka.ru/article/n/onlayn-lektsiya-kak-zhanr-internet-diskursa (дата обращения: 14.05.2021).

12. Шпенюк И. Е. Научно-академический дискурс как институциональный тип дискурса [Электронный ресурс] / И. Е. Шпенюк // Известия Гомельского государственного университета им. Ф. Скорины. 2016. № 4 (97). С. 132-137. URL: https://core.ac.uk/download/pdf/76002027.pdf (дата обращения: 10.05.2021).

13. Щербинина Ю.В. Педагогический дискурс: типическое и архетипическое [Электронный ресурс] / Ю. В. Щербинина // Наука и школа. 2010. №2. - URL: https://cyberleninka.ru/article/n/pedagogicheskiy-diskurs-tipicheskoe-i-arhetipicheskoe (дата обращения: 10.05.2021).

\section{References:}

1. Bordovskaya, N. V., Rean6 A. A. Pedagogika: Uchebnoe posobie [Pedagogy: Study guide]/ N. V. Bordovskaya, A. A. Rean. SPb.: Piter, 2008. 304 p. [in Russian]

2. Galichkina, E. N. Kharakteristiki komp'iuternogo diskursa [Characteristics of computer mediated discourse] [Electronic resource] / E. N. Galichkina // Vestnik OGU. 2004. №10, https://cyberleninka.ru/article/n/harakteristiki-kompyuternogodiskursa (accessed: 01.05.2021) [in Russian].

3. Zubkova, L. I. Konstitutivnye priznaki akademicheskogo diskursa [Distinguishing features of academic discourse]/ L. I. Zubkova // Izvestiia Volgogradskogo gosudarstvennogo pedagogicheskogo universiteta. 2009. № 5. p. 28-32 [in Russian].

4. Kutuzov, A. B. Kommunikativnye osobennosti diskursa komp'iuternykh setevykh forumov [Communicative features of network forums] [Electronic resource] / A. B. Kutuzov // III Lazarevskie chteniya. CHelyabinsk. 2006. p. 306-311, https://www. academia.edu/2984908/\%D0\%9A\%D0\%BE\%D0\%BC\%D0\%BC\%D1\%83\%D0\%BD\%D0\%B8\%D0\%BA\%D0\%B0\%D1\%82\% D0\%B8\%D0\%B2\%D0\%BD\%D1\%8B\%D0\%B5_\%D0\%BE\%D1\%81\%D0\%BE\%D0\%B1\%D0\%B5\%D0\%BD\%D0\%BD\%D0\% BE\%D1\%81\%D1\%82\%D0\%B8_\%D0\%B4\%D0\%B8\%D1\%81\%D0\%BA\%D1\%83\%D1\%80\%D1\%81\%D0\%B0_\%D0\%BA\%D 0\%BE\%D0\%BC\%D0\%BF\%D1\%8C\%D1\%8E\%D1\%82\%D0\%B5\%D1\%80\%D0\%BD\%D1\%8B\%D1\%85_\%D1\%81\%D0\%B5\% D1\%82\%D0\%B5\%D0\%B2\%D1\%8B\%D1\%85_\%D1\%84\%D0\%BE\%D1\%80\%D1\%83\%D0\%BC\%D0\%BE\%D0\%B2 (accessed: 03.05.2021) [in Russian].

5. Kulikova, L. V. Kommunikativny stil'v mezhkul'turnoi paradigme [Communication style in an intercultural paradigm] / L. V. Kulikovayu. Krasnoyarsk: Krasnoyar. gos. ped. un-t im. V.P. Astaf'eva, 2006. 392 p. [in Russian].

6. Karasik, V.I. Interpretatsiia diskursa: topik, format, modus [Discourse interpretation: topic, format, modus] [Electronic resource] / V. I. Karasik // Izvestiya VGPU. 2015. №1 (96), https://cyberleninka.ru/article/n/interpretatsiya-diskursa-topikformat-modus (accessed: 11.05.2021) [in Russian].

7. Lepsheeva, N. A. Zhanrovye osobennosti komp'iuternogo diskursa [Genre traits of computer mediated discourse] [Electronic resource] / N. A. Lepsheeva// Vestnik CHelGU. 2009. №43, https://cyberleninka.ru/article/n/zhanrovye-osobennostikompyuternogo-diskursa (accessed: 15.05.2021) [in Russian].

8. Morgun, N. L. Nauchny setevoi diskurs kak tip teksta [Scientific network discourse as a type of text]: dis. ... of PhD in Philology: 10.02.01 / Morgun Natalia Leonidovna. Tyumen', 2002, https://elibrary.com.ua/m/files/get_file/1541.pdf (accessed: 10.05.2021) [in Russian].

9. Selyutin, A. A. Prostranstvo i vremia v internet-kommunikatsii: vliianie postmodernizma [Space and time in internet communication: the impact of postmodernism] / A. A. Selutin // Vestnik CHelyabinskogo gumanitarnogo universiteta, 2012. №6 (260). p. 122-124 [in Russian].

10. Smirnov, F. O. Natsional'no-kul'turnye osobennosti elektronnoi kommunikatsii na angliiskom i russkom iazyke [National and cultural features of electronic communication in English and Russian] : dis. . of PhD in Philology. / Smirnov Fedor Olegovich. Yaroslavl', 2004. 224 p. [in Russian].

11. Talanina, A. A. Onlain-lektsiia kak zhanr internet-diskursa [Online-lecture as a genre of Internet-discourse] [Electronic resource] / A. A. Talanina // MIRS. 2018. №2, https://cyberleninka.ru/article/n/onlayn-lektsiya-kak-zhanr-internet-diskursa (accessed: 14.05.2021) [in Russian].

12. Shpenyuk, I. E. Nauchno-akademicheskii diskurs kak institutsional'ny tip diskursa [Scientific and academic discourse as an institutional type of discourse] [Electronic resource] / I. E. SHpenyuk // Izvestiya Gomel'skogo gosudarstvennogo universiteta im. F. Skoriny. 2016. № 4 (97). p. 132-137, https://core.ac.uk/download/pdf/76002027.pdf (accessed: 10.05.2021) [in Russian].

13. Shcherbinina, YU.V. Pedagogicheskii diskurs: tipicheskoe i arhetipicheskoe [Pedagogical discourse: typical and archetypal] [Electronic resource] / YU. V. Shcherbinina // Nauka i shkola. 2010. №2, https://cyberleninka.ru/article/n/pedagogicheskiydiskurs-tipicheskoe-i-arhetipicheskoe (accessed: 10.05.2021) [in Russian]. 


\section{Сведения об авторе:}

Панич Наталья Владимировна - старший преподаватель кафедры английского языка №3, МГИМО. Сфера научных интересов: прагматика и академический дискурс (англистика);

E-mail: n.v.panich@mail.ru

\section{About the author:}

Panich, Natalia Vladimirovna - Senior Lecturer at English Department №3, MGIMO University. Scholarly interests: pragmatics, academic discourse; E-mail: n.v.panich@mail.ru 